\title{
An updated review of cribriform carcinomas with emphasis on histopathological diagnosis and prognostic significance
}

\author{
Giovanni Branca, Antonio Ieni, Valeria Barresi, Giovanni Tuccari, Rosario Alberto Caruso \\ Department of Human Pathology G. Barresi, University of Messina, Italy
}

\begin{abstract}
Cribriform is a histopathological term used to describe a neoplastic epithelial proliferation in the form of large nests perforated by many quite rounded different-sized spaces. This growth pattern may be seen in carcinomas arising in different organs, and shows important prognostic implications. Therefore, recent data in literature suggest that cribriform carcinoma is a histologically and clinically distinctive type of tumour that should be separated from other similar tumour types. In this article, the pathology of cribriform adenocarcinoma of the prostate, lung, breast, stomach, colon, thyroid, and skin is discussed with particular reference to morphologic and immunohistochemical features, differential diagnosis, and clinical behaviour.
\end{abstract}

\section{Introduction}

In histopathology practice, the term cribriform (from the ancient Latin cribrum i.e. sieve) refers to neoplasms showing an architectural pattern of growth made up of straight packed glands endowed with unequally distributed lumina, lacking interposed

Correspondence: Giovanni Branca, Department of Human Pathology Gaetano Barresi, AOU Polyclinic G. Martino, Pad. D, via Consolare Valeria, 98125 Messina, Italy.

E-mail: giobranca81@gmail.com

Key words: Cribriform carcinoma; histopathology; immunohistochemistry; differential diagnosis; prognosis.

Contributions: GB designed the research, provided overall supervision, edited the manuscript; AI provided overall supervision; VB provided overall supervision; GT provided overall supervision; RAC designed the research, provided overall supervision, edited the manuscript, and performed histologic photographs.

Conflict of interest: the authors declare no potential conflict of interest.

Received for publication: 19 September 2016.

Revision received: 15 December 2016.

Accepted for publication: 6 February 2017.

This work is licensed under a Creative Commons Attribution NonCommercial 4.0 License (CC BY-NC 4.0).

CCopyright G. Branca et al., 2017

Licensee PAGEPress, Italy

Oncology Reviews 2017; 11:317

doi:10.4081/oncol.2017.317 stromal tissue (Figure 1). ${ }^{1}$ A cribriform pattern has been identified in invasive neoplasms arising in different organs..$^{2-7}$ Recently, cribriform neoplasms have been reclassified as more aggressive entities than previously reported (e.g., carcinoma of the lung, prostate, stomach, and colon). ${ }^{4,8-11}$ Therefore, the identification of a cribriform pattern may have practical prognostic implications for pathologists and oncologists. ${ }^{1}$ Our aim is to review morphological and immunohistochemical features, as well as discuss the differential diagnosis, and prognostic implications of this histologic type.

\section{Cribriform pattern in invasive prostate cancer}

Several studies have demonstrated that a cribriform pattern in radical prostatectomy specimens was associated with extraprostatic extension, positive surgical margins, distant metastases, and cancer-specific mortality. ${ }^{7,12,13}$ In 2005 , the International Society of Urological Pathology (ISUP) assigned a Gleason grade 4 rather than Gleason grade 3 for a cribriform pattern. ${ }^{8,9}$ In 2009, Lotan et al showed that there was often histologic continuity between glomeruloid glands and cribriform pattern. ${ }^{14}$ Glomeruloid pattern is a term used to describe dilated glands containing intraluminal cribriform structures with a single point of attachment, reminiscent of a renal glomerulus. ${ }^{7,14}$ Two recent studies suggest that glomeruloid structures could be considered as an early stage of cribriform Gleason pattern 4. ${ }^{14}$ Moreover, Lotan et al. showed that $84 \%$ of cases with glomeruloid glands were associated with Gleason grade 4, or higher, cancer. ${ }^{14}$ At the 2014 ISUP grading conference, assigned for glomeruloid pattern was assigned a Gleason grade $4 .^{7}$ Solid nests or cribriform structures with comedonecrosis are considered Gleason pattern $5 .^{7}$

The differential diagnosis for atypical cribriform lesions of the prostate has become increasingly complex and includes intraductal carcinoma of the prostate (IDC-P), high-grade prostatic intraepithelial neoplasia (HG-PIN), ductal carcinoma, and acinar cell carcinoma with cribriform pattern. ${ }^{15,16}$ Invasive acinar adenocarcinoma may closely mimic IDC-P when it has a cribriform or solid architecture. The key difference between IDC-P and invasive acinar adenocarcinoma with cribriform/glomeruloid pattern is a lack of any basal cell layer present in invasive acinar adenocarcinoma. ${ }^{7,15,17,18}$ IDC-P must be distinguished from HG-PIN. Usually, in HG-PIN tumour cells are uniformly atypical with nuclear size 2-3 times normal adjacent nuclei, whereas in IDC-P there is a marked pleomorphism with nuclear size $>6$ times normal adjacent nuclei. ${ }^{15,17,19,20}$ Moreover, HG-PIN involves few glands, whereas IDC-P frequently involves $>6$ glands. ${ }^{15}$ Comedonecrosis and mitoses are rarely seen in HG-PIN, whereas they are easily identifiable in IDC-P. ${ }^{15,17-20}$ Immunohistochemical staining for PTEN may be useful in difficult cases, as it remains positive in HG-PN and is negative in IDC-P. ${ }^{15,18,20,21}$ Table 1 summarizes the 
morphologic and immunohistochemical features that are useful in the differential diagnosis between HG-PIN, IDC-P, ductal carcinoma and acinar cell carcinoma with cribriform architecture.

\section{Invasive cribriform carcinoma of the breast}

Invasive cribriform carcinoma is a rare histological type of invasive breast cancer accounting for less than $4 \%$ of all breast cancers. ${ }^{3,22,23}$ Histologically, it is characterized by angulated epithelial nests composed of mild to moderate atypical cells arranged in a sieve-like pattern, which are surrounded by a fibrosclerotic stroma. ${ }^{3}$ Typically, neoplastic cells with apical snouts as well as lumina occupied by microcalcification and mucin-like substance can be recognized. ${ }^{3,24}$ Immunohistochemically, cancerous nests are positive for cytokeratins, and strongly for estrogen, as well as for progesteron receptors, but myoepithelial markers such as p63 and smooth muscle actin are not expressed. ${ }^{24}$ Breast invasive cribriform carcinoma is subdivided into three forms: the pure invasive type (whenever $>90 \%$ of a cribriform pattern of the entire lesion), the invasive type (i.e., cribriform pattern plus a component of tubular carcinoma $<50 \%$ ), and the mixed type (characterized by $10-49 \%$ of a carcinoma with histotype other than tubular). ${ }^{3}$ Generally, this neoplasm has a better prognosis compared to invasive carcinoma of no special type (10year overall survival results between $90 \%$ and $100 \%$ ) even if the mixed type showed a worse prognosis between the two forms. ${ }^{3,24}$ Pleomorphism is minimal or absent, and nuclear grade I is present in at least $90 \%$ of cells. Mitotic figures are unusual. According to biomolecular classification of breast neoplasms, invasive cribriform carcinoma is mainly of the luminal A-type (luminal B-type has also been described), since estrogen and progesteron receptors are positively immunoexpressed in contrast to a negative hyperexpression/amplification for Her2 receptors. ${ }^{3,22,24}$

Table 2 shows the main differential diagnostic considerations on adenoid cystic carcinoma, neuroendocrine tumours, and cribriform ductal carcinoma in situ and invasive. 3,23,25-27

\section{Cribriform pattern in lung adenocarcinoma}

Histology-based 2015 World Health Organization (WHO) classification of lung tumours identifies five histotypes: e.g., lepidic, acinar, papillary, micropapillary, and solid, whereas a cribriform pattern is considered a rare variant of the acinar adenocarcinoma. ${ }^{5,10}$ Warth et al identified predominant and minor patterns of lepidic, acinar, micropapillary, solid and cribriform components in a series of 674 resected adenocarcinomas. ${ }^{28}$ Only 28 cases $(4.2 \%)$ were cribriform predominant, although a minor component was frequently observed (28.6\% of all cases). ${ }^{28}$ Moreover, a cribriform pattern must be distinguished by metastatic cribriform neoplasms of other sites, including breast, prostate, ovary, pancreas, uterus, colon, and thyroid. Histologically, primary cribriform adenocarci-

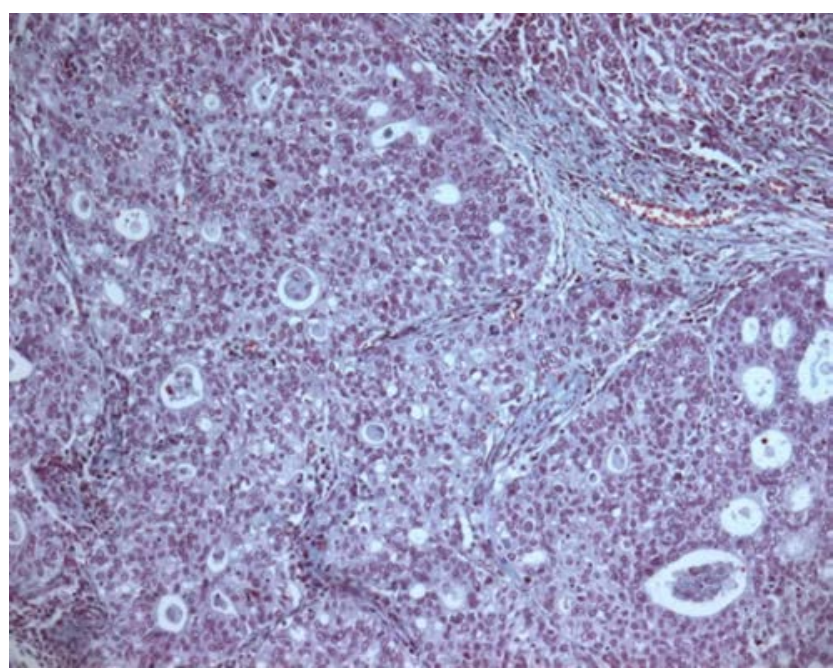

Figure 1. Gastric carcinoma with a cribriform component. Note nests of epithelial cells with round spaces producing cribriform pattern (Hematoxylin and eosin staining; magnification, x100).

Table 1. Differential diagnosis among cribriform neoplasms of the prostate.

\begin{tabular}{|c|c|c|c|c|}
\hline HGPIN & IDC-P & Ductal carcinoma & $\begin{array}{l}\text { Acinar carcinoma } \\
\text { (cribriform pattern) }\end{array}$ & \\
\hline $\begin{array}{l}\text { Growth pattern } \\
\text { or loose cribriform. }\end{array}$ & $\begin{array}{l}\text { Usually micropapillary } \\
\text { or Loose cribriform/ } \\
\text { micropapillary }\end{array}$ & $\begin{array}{l}\text { Solid/dense cribriform } \\
\text { slitlike spaces } \\
\text { (endometrioid pattern) }\end{array}$ & $\begin{array}{l}\text { Papillary, solid or cribriform with } \\
\text { pattern (Gleason pattern 4) }\end{array}$ & Cribriform and glomeruloid \\
\hline Comedonecrosis & No & Frequent non-focal & $\begin{array}{l}\text { Present } \\
\text { (invasive cribriform carcinoma) }\end{array}$ & Present in Gleason pattern 5 \\
\hline Basal cell layer & Intact or fragmented & At least partial & Absent & Absent \\
\hline Gland size & Similar to adjacent normal glands & Expanded, branching & Large gland & Small glands \\
\hline Cytological features & Cuboidal & Cuboidal cells & Tall columnar cells & Cuboidal cells \\
\hline Nuclear features & 2-3 times normal & $>6$ times normal & Elongated & Enlarged \\
\hline Nucleoli & Prominent & Prominent & Prominent & Prominent \\
\hline Mitoses & Rare & Few/frequent & Frequent & Frequent \\
\hline \multicolumn{5}{|l|}{ Immunohistochemistry } \\
\hline PSA & Positive & Positive & Positive & Positive \\
\hline AMACR & Positive & Positive & Positive & Positive \\
\hline PTEN & Positive & Negative in $61-84 \%$ & Negative & Data unavailable \\
\hline Basal markers & Positive & Positive & Negative & Negative \\
\hline
\end{tabular}


nomas could show structures similar to: i) cribriform prostatic or breast adenocarcinomas, such as roman bridges and comedonecrosis; ii) mucinous adenocarcinomas of the pancreas or ovary such as garland-like distribution at the tumour periphery; iii) endometrioid adenocarcinomas such as subnuclear vacuoles and comedonecrosis; iv) colorectal adenocarcinomas such as dirty necrosis and scattered goblet cells; v) papillary thyroid carcinoma such as clearing of nuclear chromatin and overlapping of the nuclei. ${ }^{10}$ However, a primary lung phenotype can be confirmed by immunohistochemistry (i.e., TTF1+/CK7+/napsin A+) and negative results for other markers. $.5,10,29$

The correlation between cribriform predominant pattern and ALK expression, EGFR or KRAS mutations is a controversial issue. Mackinnon was unable to find a specific molecular signature for cribriform predominant carcinomas, whereas Warth et al. showed high rates of KRAS and no EGFR mutations. ${ }^{10,28}$ ALKpositive pulmonary adenocarcinomas were more frequently observed in tumours characterized by mixed growth pattern including acinar, solid, micropapillary, and cribriform. ${ }^{10,28,30}$ Due to its rarity and controversy over classification, further studies are needed to verify specific associations of molecular signatures with a cribriform pattern. Recent studies suggest that cribriform pattern is associated with aggressive behavior. ${ }^{5,10}$ Kadota et al. showed that cribriform predominant adenocarcinoma is characterized by a higher mitotic rate, vascular invasion, and tissue necrosis compared to acinar predominant adenocarcinoma. ${ }^{1}$ In particular, Warth et al. showed that cribriform histotype heavily influences outcome, and propose that a cribriform pattern would be better included in high-grade tumours such as solid and micropapillary patterns rather than in the acinar group, as currently suggested by WHO classification. ${ }^{28}$ Based on promising data demonstrating peculiar clinicopathologic features, several authors suggest the identification of a cribriform pattern as a specific histotype in future WHO lung tumours classifications.

\section{Cribriform-morular variant of papillary thyroid carcinoma}

This name is referred to a rare variant of papillary thyroid carcinoma (corresponding to less than $0.5 \%$ of whole papillary thyroid carcinomas) that occurs sporadically, mainly in young women, or in association with FAP or Gardner syndrome, which, in the last WHO classification of endocrine tumours, is denominated simply cribriform carcinoma.$^{6,31,32}$ The prognosis as well as the biomolecular alterations (i.e., presence of RET/PTC translocation, and no BRAF mutations) are similar to those discovered in classical papillary thyroid carcinoma. ${ }^{6}$ Histological findings of this tumour other than the cribriform pattern of growth are: cuboidal to columnar shaped cells, the observation of intratumoral squamoid islands called morules (although they are squamous in morphology, they are devoid of keratinization or of cellular bridges), the eosinophilic biotin-containing inclusion of some nuclei localized within the morules, hyperchromatic/pseudostratified nuclei, focal nuclei with hallmark of papillary carcinoma (i.e., clearing, grooves, intranuclear cytoplasmic inclusions), absence or scarcity of colloid, lack of mitotic activity and necrosis, and encapsulated well circumscribed edges with or without capsular and/or vascular invasion. ${ }^{6,31-35}$ Immunohistochemically, neoplastic follicular cells are stained with antibodies against thyroglobulin (although with variable results), as well as for CK19 and TTF-1. ${ }^{31-33,36}$ Intriguingly, the morular cells express CA-19.9 and CD10, whilst they are immunonegative for epithelial membrane antigen, high molecular weight cytokeratins, and vimentin. ${ }^{32}$ An aberrant nuclear expression for betacatenin evidences an alteration in APC/Wnt pathway. ${ }^{32}$ The main differential diagnosis is between the tall and columnar cells variant of papillary thyroid carcinoma. ${ }^{32,33}$ Tall cell variant shows neoplastic cells with heights at least three times more compared to their widths, mainly papillary pattern of growth, lack of cribriform as well as morular structures, diffuse nuclear alterations typical of classical papillary thyroid carcinoma, basally located nuclei, necrotic areas, mitotic activity, diffuse immunostaining for thyroglobulin, detection of BRAF mutation, major incidence in older men, and, aggressive behavior. ${ }^{6,31-33}$

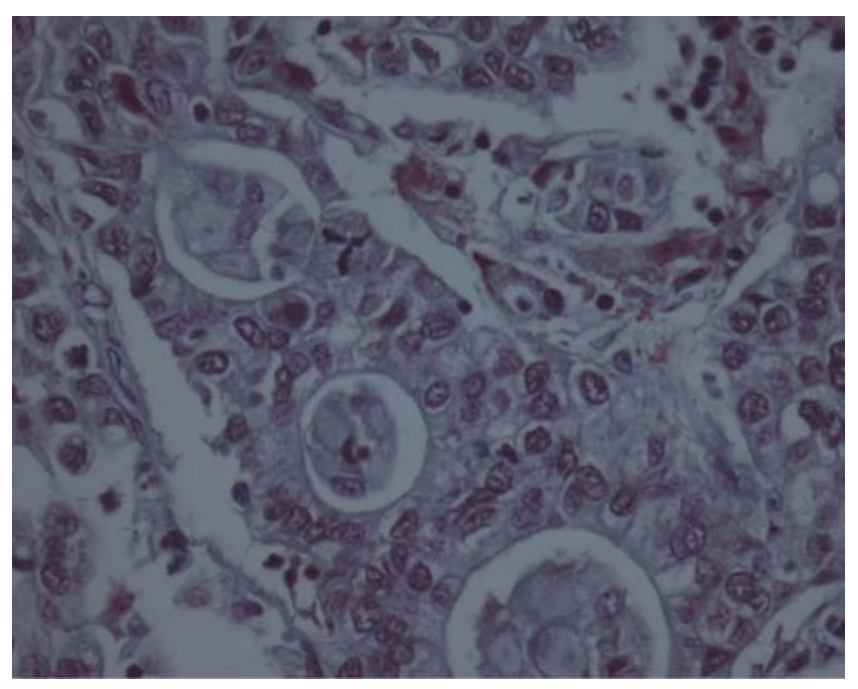

Figure 2. Cribriform gastric carcinoma with tripolar mitosis (Hematoxylin and eosin staining; magnification, $x 400$ ).

Table 2. Differential diagnosis of invasive cribriform carcinoma of the breast. Histological type Microscopy

\section{Adenoid cystic carcinoma}

Invasive neuroendocrine tumours

Cribriform adenocarcinoma
Round-shaped spaces containing dPAS positive basement membrane-like substance surrounded by two cell types (myoepithelial basaloid and eosinophilic cells) No ductal carcinoma in situ

Nests/trabeculae of spindle, plasmacytoid or large clear cells

Absence of dPAS positive cores Ductal carcinoma in situ may be present Immunohistochemistry

cKit positive cells;

p63, calponin, CK 5/6 positive myoepithelial cells

Estrogen and progesterone receptors generally negative

Synaptophysin and chromogranin positivity

No cKit positivity

Myoepithelial cells absent on immunohistochemical stains Estrogen and progesterone receptors positive 
Instead, the columnar variant is typically characterized by supra and/or subnuclear vacuolization of pseudostratified hyperchromatic elongated cells, resembling those observed in early secretive stage of endometrial glands, which are well decorated by TTF1 antigen, but variably for thyroglobulin. 6,31,32 Moreover this variant of PTC is devoid of any cribriform-morular pattern, and shows an aggressive behavior. ${ }^{31,33,34}$

\section{Gastric carcinoma with cribriform component}

A cribriform component in gastric adenocarcinoma morphologically similar to mammary intraductal carcinoma, is a rare pattern of growth recognized in this organ, which to date has been described only in a small cohort of intestinal type adenocarcinomas by Lino-Silva et al. ${ }^{4}$ Moreover this histopathological pattern was not described in the last WHO Classification of Tumours of Gastrointestinal tract. ${ }^{37}$ Gastric carcinoma with a cribriform component is mainly diagnosed in adult men in an age similar to that observed for common gastric adenocarcinoma, always associated with an intestinal type carcinoma component, and not correlated with histological hallmarks of Helicobacter pylori infection in the adjacent mucosa (e.g., follicular gastritis, gastric atrophy, intestinal metaplasia). ${ }^{4}$ Furthermore, gastric carcinoma with a cribriform pattern shows a major tendency to possess a higher stage, lymphovascular and perineural invasion, and a lower disease free survival rate, in comparison to conventional gastric carcinoma. ${ }^{4}$ Figure 2 shows a gastric carcinoma with a cribriform component characterized by atypical mitosis (Figure 2). From an immunohistochemical viewpoint, tumour cells are diffusely decorated with CK7 and CK19, but focally for CK20. ${ }^{4}$ Positivity for MUC5AC has also been described, whereas the estrogen and progesterone receptors, CDX2, MU1, MUC2, and GCDFP-15 are not expressed. ${ }^{4}$ The most important differential diagnosis for gastric carcinoma with cribriform component is with a metastatic breast cribriform carcinoma. ${ }^{3,4}$ However, the presence of an in situ adenocarcinoma component together with an immunonegative expression for the usual markers of breast carcinoma such as mammoglobin, progesterone and estrogen receptors, and GCDPF-15, are all useful elements for diagnosing primitive gastric adenocarcinoma with cribriform component. ${ }^{4}$

\section{Colonic cribriform comedo-type adenocarcinoma}

This histotype has been briefly described in the current WHO Classification of Tumours of the Digestive System, and defined as an adenocarcinoma in which is recognized a cribriform pattern with a central area of comedo-like necrosis similar to that observed in mammary intraductal carcinoma. ${ }^{2}$ Recently, a study by LinoSilva et al. has highlighted a negative outcome for this entity. ${ }^{11}$ Moreover, the majority of the cases enrolled in that study showed adverse prognostic findings such as high stage, lymphovascular invasion, lymph nodes metastasis in $>5$ of the harvested ones, and lower 5-year survival than conventional adenocarcinomas histotype. ${ }^{11}$ Moreover, Kim et al. demonstrated a negative prognostic impact for those colorectal carcinomas with a cribriform component characterized by microsatellite instability high (MSI-H), in terms of shorter disease-free survival. ${ }^{38}$

\section{Primary cutaneous cribriform carcinoma}

Cutaneous cribriform carcinoma, recently described in 1998, is considered as a variant of sweat gland carcinoma, characterized by excellent outcome without recurrence and/or metastasis. ${ }^{39,40}$ The main histopathological findings of this tumour are the following: i) partially or relatively well-circumscribed, non-encapsulated dermal nodule; ii) nests of epithelioid cells owning lumina; iii) pleomorphic elongated nuclei; iv) desmoplastic stroma; v) rare mitoses; vi) none lymphovascular or perineural invasion. ${ }^{39,40}$ Immunohistochemical stains for CK5/6 and 7, CEA and EMA (luminal), C-kit (CD117) BerEp4, and S100 reveal positivity in tumour cells; CK20 invariably shows negativity. ${ }^{39}$ Primary cutaneous cribriform carcinoma should be distinguished from primary cutaneous adenoid cystic carcinoma. ${ }^{39,40,41}$ However, the latter histologic type is characterized by high recurrence risk, infiltrative growth pattern, rare lymph node and lung metastases, perineural infiltration. ${ }^{39,40,41}$ Moreover, the tumour consists of basaloid cells surrounding hyaline, periodic acid-Schiff positive basement membrane-like substance or alcian blue $(\mathrm{pH} 2.5)$ positive mucins. ${ }^{41}$ Immunohistochemistry is not helpful for the differential diagnosis against cribriform carcinoma.

\section{Conclusions}

The diagnostic approach of pathologists in their daily practice is based on the analysis of architectural and cytological features, immunohistochemical stains and other ancillary techniques in the contest of knowledge of the clinical background of the case. Recently, cribriform pattern has emerged as a paradigmatic example of an additional adverse prognostic factor in adenocarcinomas of various organs, such as prostate, lung, stomach, colon. Instead, patients with breast cribriform carcinoma have significantly better survival rates than patients with invasive ductal cancer (not otherwise specified), whereas the prognosis of a cribriform-morular variant of papillary thyroid carcinoma is similar to that of classical papillary thyroid carcinoma. Thus, cribriform carcinoma is not only a morphologic tumour growth pattern, but also a prognostic factor. More research is required to evaluate the prognostic implications of a diagnosis of cribriform carcinoma in other organs such as in the skin. However, practicing pathologists should be aware that cribriform tumours of prostate, lung, stomach and colon are clinically aggressive, in order to diagnose and treat an affected patient correctly.

\section{References}

1. Kadota K, Yeh YC, Sima CS, et. al. The cribriform pattern identifies a subset of acinar predominant tumors with poor prognosis in patients withstage I lung adenocarcinoma: a conceptual proposal to classify cribriform predominant tumors as a distincthistologic subtype. Mod Pathol 2014;27:690-700.

2. Hamilton SR, Bosman FT, Boffetta P, et al. Carcinoma of the colon and rectum. In: Bosman FT, Carneiro F, Hruban RH, Theise ND, eds. WHO Classification of Tumours of the Digestive System. Lyon: IARC; 2010. p 138.

3. Rakha E, Pinder SE, Shin SJ, Tsuda H. Tubular carcinoma and cribriform carcinoma. In: Lakhani SR, Ellis LO, Schnitt SJ, Tan PH, van de Vijver MJ, eds. WHO Classification of Tumours of the Breast. Lyon: IARC; 2012. pp 44-5.

4. Lino-Silva LS, Salcedo Hernández RA, Molina-Frías E. Mixed gastric carcinoma with intestinal and cribriform patterns: a distinctive pathologic appearance associated with poor prognosis in advanced stages and a potential mimicker of metastatic 
breast carcinoma. Int J Surg Pathol 2013;2:6-14.

5. Travis WD, Noguchi M, Yatabe Y, et al. Adenocarcinoma. In: Travis WD, Brambilla E, Burke AP, Marx A, Nicholson AG, eds. WHO Classification of tumours of the lung, pleura, thymus and Heart. Lyon: IARC; 2015. pp 26-37.

6. Sak SD. Variants of papillary thyroid carcinoma: multiple faces of a familiar tumor. Turk Patoloji Derg 2015;31:34-47.

7. Humphrey PA, Amin MB, Berney DM, et al. Acinar adenocarcinoma. In: Moch H, Humphrey PA, Ulbright TM, Reuter VE, eds. WHO Classification of Tumours of the Urinary System and Male Genital Organs. Lyon: IARC; 2016. pp138-62.

8. Kir G, Sarbay BC, Gümü_E, Topal CS. The association of the cribriform pattern with outcome for prostatic adenocarcinomas. Pathol Res Pract 2014;210:640-4.

9. Sarbay BC, Kir G, Topal CS, Gumus E. Significance of the cribriform pattern in prostatic adenocarcinomas. Pathol Res Pract 2014;210:554-7.

10. Mackinnon AC Jr, Luevano A de Araujo LC, et al. Cribriform adenocarcinoma of the lung: clinicopathologic, immunohistochemical, an dmolecular analysis of 15 cases of a distinctive morphologic subtype of lung adenocarcinoma. Mod Pathol 2014;27:1063-72.

11. Lino-Silva LS, Salcedo-Hernández RA, Herrera-Gómez A, et al. Colonic cribriform carcinoma, a morphologic pattern associated with low survival. Int J Surg Pathol 2015;23:13-9.

12. Keefe DT, Schieda N, El Hallani S, et al. Cribriform morphology predicts upstaging after radical prostatectomy in patients with Gleason score $3+4=7$ prostate cancer at transrectal ultrasound (TRUS)-guided needle biopsy. Virchows Arch 2015,467:437-42.

13. Kweldam CF, Kümmerlin IP, Nieboer D, et al. Disease-specific survival of patients with invasive cribriform and intraductal prostate cancer at diagnostic biopsy. Mod Pathol 2016;29:6306.

14. Lotan TL, Epstein JI. Gleason grading of prostatic adenocarcinoma with glomeruloid features on needle biopsy. Hum Pathol 2009;40:471-7.

15. Magers M, Kunju LP, Wu A. Intraductal carcinoma of the prostate: morphologic features, differential diagnoses, significance, and reporting practices. Arch Pathol Lab Med 2015;139:1234-41.

16. Egevad L, Epstein JI, Hameed O, et al. Ductal adenocarcinoma. In: Moch H, Humphrey PA, Ulbright TM, Reuter VE, eds. WHO Classification of Tumours of the Urinary System and Male Genital Organs. Lyon: IARC; 2016. pp. 166-7.

17. Guo CC, Epstein JI. Intraductal carcinoma of the prostate on needle biopsy: histologic features and clinical significance. Mod Pathol 2006;19:1528-35.

18. Epstein JI, Oxley J, Ro JY, et al. Intraductal carcinoma. In: Moch H, Humphrey PA, Ulbright TM, Reuter VE, eds. WHO Classification of Tumours of the Urinary System and Male Genital Organs. Lyon: IARC; 2016. pp. 164-5.

19. Bostwick DG, Qian J. High-grade prostatic intraepithelial neoplasia. Mod Pathol 2004;17:360-79.

20. Bostwick DG, Humphrey PA, Montironi R, Srigley JR. Highgrade prostatic intraepithelial neoplasia. In: Moch $\mathrm{H}$, Humphrey PA, Ulbright TM, Reuter VE, eds. WHO Classification of Tumours of the Urinary System and Male Genital Organs. Lyon: IARC; 2016. pp. 162-3.

21. Lotan TL, Gumuskaya B, Rahimi H, et al. Cytoplasmic pten protein loss distinguishes intraductal carcinoma of the prostate from high grade prostatic intraepithelial neoplasia. Mod Pathol 2013;26:587-603.

22. Liu XY, Jiang YZ, Liu YR, et al. Clinicopathological charac- teristics and survival outcomes of invasive cribriform carcinoma of breast: a SEERPopulation-Based Study. Medicine (Baltimore) 2015;94:e1309.

23. Cong Y, Qiao G, Zou H, et al. Invasive cribriform carcinoma of the breast: a report of nine cases and a review of the literature. Oncol Lett 2015;9:1753-8.

24. Zhang W, Zhang T, Lin Z, et al. Invasive cribriform carcinoma in a Chinese population: comparison with low-grade invasive ductal carcinoma-not otherwise specified. Int J Clin Exp Pathol 2013;6:445-57.

25. Sapino A, Sneige N, Eusebi V. Adenoid cystic carcinoma. In: Lakhani SR, Ellis LO, Schnitt SJ, Tan PH, van de Vijver MJ, eds. WHO Classification of Tumours of the Breast. Lyon: IARC; 2012. pp. 56-7.

26. Bussolati G, Badve S. Carcinomas with neuroendocrine features. In: Lakhani SR, Ellis LO, Schnitt SJ, Tan PH, van de Vijver MJ, eds. WHO Classification of Tumours of the Breas. Lyon: IARC; 2012. pp 62-3.

27. Schnitt SJ, Allred C, Britton P, et al. Ductal carcinoma in situ. In: Lakhani SR, Ellis LO, Schnitt SJ, Tan PH, van de Vijver MJ, eds. WHO Classification of Tumours of the Breast. Lyon: IARC; 2012. Pp. 90-4.

28. Warth A, Muley T, Kossakowski C, et al. Prognostic impact and clinicopathological correlations of the cribriform pattern in pulmonary adenocarcinoma. J Thorac Oncol 2015;10:638-44.

29. Pelosi G, Fukuoka J, Hiroshima K, Marchevsky AM. Metastases to the lung. In: Travis WD, Brambilla E, Burke AP, Marx A, Nicholson AG, eds. WHO Classification of tumours of the lung, pleura, thymus and Heart. Lyon: IARC; 2015. pp. 148-9.

30. McLeer-Florin A, Moro-Sibilot D, Melis A, et al. A Dual IHC and FISH testing for ALK gene rearrangement in lung adenocarcinomas in a routine practice: a French study. J Thorac Oncol 2012;7:348-54.

31. LiVolsi VA, Albores-Saavedra J, Asa SL, et al. Papillary carcinoma. In: DeLellis RA, Lloyd RV, Heitz PU, Eng C, eds. World Health Organization Classification of Tumours. Pathology and Genetics of Tumours of Endocrine Organs. Lyon: IARC; 2004. pp 57-66.

32. Cameselle-Teijeiro J, Menasce LP, Yap BK, et al. Cribriformmorular variant of papillary thyroid carcinoma: molecular characterization of a case with neuroendocrine differentiation and aggressive behavior. Am J Clin Pathol 2009;131:134-42.

33. Chikkamuniyappa S, Jagirdar J. Cribriform-morular variant of papillary carcinoma: association with familial adenomatous polyposis - report of three cases and review of literature. Int J Med Sci 2004;1:43-9.

34. Cameselle-Teijeiro J, Ruiz-Ponte C, Loidi L, et al. Somatic but not germline mutation of the APC gene in a case of cribriformmorular variant of papillary thyroid carcinoma. Am J Clin Pathol 2001;115:486-93.

35. Nikiel B, Chekan M, Jarzab M, Lange D. Endogenous avidin biotin activity (EABA) in thyroid pathology: immunohistochemical study. Thyroid Res 2009;2:5.

36. Subramaniam MM, Putti TC, Anuar D, et al. Clonal characterization of sporadic cribriform-morular variant of papillary thyroid carcinoma by lasermicrodissection-based APC mutation analysis. Am J Clin Pathol 2007;128: 994-1001.

37. Lauwers GY, Carneiro F, Graham DY, et al. Gastric carcinoma. In: Bosman FT, Carneiro F, Hruban RH, Theise ND, eds. WHO Classification of Tumours of the Digestive System. Lyon: IARC; 2010. Pp. 52-4.

38. Kim JH, Bae JM, Oh HJ, et al. Pathologic factors associated with prognosis after adjuvant chemotherapy in stage ii/iii 
microsatellite-unstablecolorectal cancers. J Pathol Transl Med 2015;49:118-28.

39. Arps DP, Chan MP, Patel RM, Andea AA. Primary cutaneous cribriform carcinoma: report of six cases with clinicopathologic data and immunohistochemical profile. J Cutan Pathol 2015;42:379-87.

40. Cacchi C, Persechino S, Fidanza L, Bartolazzi A. A primary cutaneous adenoid-cystic carcinoma in a young woman.
Differential diagnosis and clinical implications. Rare Tumors 2011;3:e3.

41. Requena L, Kutzner H, Hurt MA, et al. Malignant tumours with apocrine and eccrine differentiation. In: LeBoit PE, Burg G, Weedon D, Sarasain A, eds. World Health Organization Classification of Tumours. Pathology and Genetics of Skin Tumours. Lyon: IARC; 2006. pp 134-35. 